\title{
Is pharmacist pre-registration training equitable and robust?
}

DOI:

10.1108/heswbl-07-2018-0071

\section{Document Version}

Accepted author manuscript

Link to publication record in Manchester Research Explorer

\section{Citation for published version (APA):}

Jee, S., Schafheutle, E., \& Noyce, P. (2019). Is pharmacist pre-registration training equitable and robust? Higher Education, Skills and Work-Based Learning. https://doi.org/10.1108/heswbl-07-2018-0071

\section{Published in:}

Higher Education, Skills and Work-Based Learning

\section{Citing this paper}

Please note that where the full-text provided on Manchester Research Explorer is the Author Accepted Manuscript or Proof version this may differ from the final Published version. If citing, it is advised that you check and use the publisher's definitive version.

\section{General rights}

Copyright and moral rights for the publications made accessible in the Research Explorer are retained by the authors and/or other copyright owners and it is a condition of accessing publications that users recognise and abide by the legal requirements associated with these rights.

\section{Takedown policy}

If you believe that this document breaches copyright please refer to the University of Manchester's Takedown Procedures [http://man.ac.uk/04Y6Bo] or contact uml.scholarlycommunications@manchester.ac.uk providing relevant details, so we can investigate your claim.

\section{OPEN ACCESS}




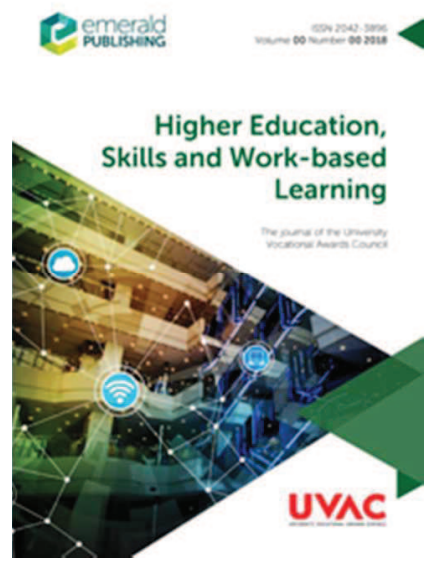

\section{Is pharmacist pre-registration training equitable and robust?}

\begin{tabular}{|r|l|}
\hline Journal: & Higher Education, Skills and Work-Based Learning \\
\hline Manuscript ID & HESWBL-07-2018-0071.R1 \\
\hline Manuscript Type: & Research Paper \\
\hline Keywords: & $\begin{array}{l}\text { pharmacy pre-registration training, pharmacy education, trainee } \\
\text { pharmacist, pharmacy work based learning }\end{array}$ \\
\hline \multicolumn{2}{|l}{} \\
\hline
\end{tabular}




\section{Is pharmacist pre-registration training equitable and}

2 robust?

\section{Purpose}

5 Against a backdrop of concerns regarding the quality and equity of the final practice-

6 based pre-registration training year, this paper examines how robust and equitable

7 current education and training arrangements in Great Britain are in preparing newly

8 qualified pharmacists for practice.

\section{Design/methodology/approach}

10 In addition to considering relevant regulator, policy and research literature, this paper

11 presents findings from a longitudinal qualitative study that tracked 20 pharmacy

12 trainees and their tutors during pre-registration training and early registered practice.

13 Trainees were interviewed 4 times over a 12-month period; tutors were interviewed

14 twice. Semi-structured interviews explored learning and development, work

15 environment and support received. Interview transcripts were analysed thematically

16 using template analysis.

\section{Findings}

18 Currently, there are no requirements tor training pre-registration tutors, or for 19 accreditation or quality assurance of training sites. Longitudinal interview findings 20 showed that community trainees developed knowledge of over-the-counter, and less 21 complex, medicines whereas hospital trainees learnt about specialist medicines on 22 ward rotations. Hospital trainees received support from a range of pharmacists, 23 overseen by their tutor, and other healthcare professionals. Community trainees 24 generally worked within a small pharmacy team, closely supervised by their tutor, 25 who was usually the sole pharmacist. Newly qualified pharmacists were challenged 26 by having full responsibility and accountability as independent practitioners, without 27 formal support mechanisms.

\section{Originality/value}

29 The variability in trainee experience and exposure across settings raises concerns 30 over the robustness and equity of pre-registration training. The lack of formal 
31 support mechanisms post-registration may pose risks to patient safety and

32 pharmacists' wellbeing.

331 Introduction

34 Ensuring healthcare education and training is fit for purpose and quality assured

35 supports the development of learners and allows them to perform their roles safely

36 and effectively upon professional registration (Greiner et al. 2003). The role of

37 healthcare professionals has changed over the years as patients have become more

38 empowered and have played a more integral role in their own care (Adams and

39 Grieder 2014). The role of the pharmacy profession, in particular, has evolved, with

40 pharmacists in Great Britain (GB) being increasingly clinically trained and playing an

41 integral part in patient care (Toklu and Hussain 2013). In hospitals, pharmacists

42 provide ward-based, clinical services to patients as part of multidisciplinary teams.

43 In community pharmacy, pharmacists provide minor ailment, public health and

44 medicines services, supporting patients with long-term conditions and helping in the

45 detection of serious illnesses. Pharmacists are also practising increasingly more

46 clinically in primary care services, such as General (Family) Practice (GP), care

47 homes and urgent care (Anon 2016).

48 Healthcare education curricula have progressed to support the development of skills

49 necessary for safe and effective practice. Medicine, for example, began adopting

50 different methods of teaching (e.g. problem-based/ blended learning) about 20 years

51 ago, moving away from predominantly didactic methods (Burge 2003;Lloyd-Jones

52 2005). More recently in GB, undergraduate pharmacy curricula have been reformed

53 to achieve the move to outcome-focussed education and training regulatory

54 standards (General Pharmaceutical Council 2011). Evidence is beginning to emerge

55 to show that these reformations have desirable effects in better preparing graduates

56 for practice (Parmar et al. 2016;Parmar 2016). The introduction of outcomes-

57 focussed standards by the General Pharmaceutical Council (GPhC), the pharmacy

58 regulator in $\mathrm{GB}$, has led to significant curricular reform of the 4-year undergraduate

59 Master of Pharmacy (MPharm). However, comparable changes do not appear to

60 have taken place in the 5th year of pharmacy pre-registration training (Greiner,

61 Knebel, Committee on the Health Professions Education Summit, \& Board on Health

62 Care Services 2003;Toklu \& Hussain 2013). It is, therefore, important to consider 
63 how this final in-practice year is supporting the development of appropriate 64 competences necessary for safe and effective practice.

65 By focussing on the pre-registration year, this paper aims to examine how robust 66 current education and training arrangements for pharmacists in GB are and whether 67 they adequately prepare newly qualified pharmacists (NQPs) for practice as 68 independent practitioners in any sector. This paper draws on pharmacy education and training policy and publications to describe current pre-registration training 70 context and arrangements. It then draws in particular on a recent multi-methods, 72 pharmacists develop into pharmacists.

\subsection{Education and training requirements prior to registration in GB} In order to register as a pharmacist in Great Britain, individuals must undertake 4 years of university based education and 1 year of pre-registration training. At the end of this final year, pre-registration trainees must sit and pass a national GPhC-set registration assessment, which tests that they can demonstrate the appropriate application of knowledge and understanding to make professional judgements in practice (General Pharmaceutical Council 2018b).

The registration assessment takes place in June and September every year, with most trainees sitting their first attempt in June. Due to an increase in the number of schools of pharmacy - and thus increasing numbers of MPharm graduates over recent years - the number of trainees sitting the assessment has also increased.

84 Pass rates for the first attempt have been variable and there has been notable drops 85 in pass rates, such as from 2016-2017 (Figure 1) (General Pharmaceutical Council 2018a).

\section{7 [Insert Figure 1 about here]} Inconsistencies in registration assessment pass rates are a cause for concern and have increased the debate about its utility. Changes to the registration assessment were introduced from June 2016, using a new format and methodology announced in December 2014, with the aim of assessment better reflecting patient-facing pharmacy practice (General Pharmaceutical Council 2018a). Nevertheless, despite 93 a pass rate of $95 \%$ in June 2016 , this dropped back down to $78 \%$ and $79 \%$ in June 942017 and 2018 respectively. 
95 A further point of contention surrounding the registration assessment was the 96 GPhC's decision in 2015 to publish, for the first time, assessment pass rates for 97 2011-2014 associated with individual schools of pharmacy (General Pharmaceutical 98 Council 2015b). This showed that pass rates, depending on the MPharm awarding 99 university, ranged between $54 \%$ and $90 \%$. Furthermore, the GPhC also published 100 assessment success rates depending on the sector of pre-registration training for 1012015 (General Pharmaceutical Council 2015a). This showed that $91 \%$ of those who 102 had completed their pre-registration training year in hospital passed, compared to 103 only $71 \%$ of those who had trained in community pharmacy (Andalo 2015; General 104 Pharmaceutical Council 2015a;Torjesen 2015). This raises questions as to whether 105 there are differences in pre-registration training between these settings that support 106 the likelihood of passing the assessment, the calibre of trainees that end up training 107 in these sectors and potential biases in the assessment that favour a particular 108 sector.

\subsection{Overview of the pre-registration year}

110 The pre-registration year typically follows the completion of a 4-year (full-time)

111 university-based MPharm degree, which provides pharmacy students with relatively

112 little practice exposure,(Schafheutle et al. 2012; Schafheutle et al. 2013) and trainees

113 holding the view that the MPharm lacks a focus on clinical and practice subjects

114 (McAteer et al. 2004). Despite recent changes to MPharm curricula, a lot of

115 emphasis continues to be placed on the pre-registration year to support the

116 professional development of pharmacy graduates prior to registration.

117 The pre-registration year is 52 weeks of practice-based training where at least 26

118 weeks must be in a patient-facing sector (General Pharmaceutical Council 2011).

119 There are different modes of training (General Pharmaceutical Council 2011), but the

120 majority of trainees undertake a full year of training in either community or hospital

121 pharmacy. Trainees are salaried during their pre-registration training and funding

122 comes from NHS England (Pharmacist Support 2018), NHS Scotland (NHS

123 Education for Scotland 2018), and NHS Wales (Pharmacist Support 2018). Hospital

124 trainees are typically paid more than those in community (Pharmacist Support 2018).

125 During training, each trainee is allocated a pre-registration tutor by the employing 126 pharmacy who is responsible for their supervision and assessment which involves 
127 carrying out, and signing off, 3 13-weekly appraisals and 1 final declaration

128 confirming the trainee is deemed fit to join the register. Trainees have to

129 demonstrate competence in 76 performance standards that cover areas of personal

130 effectiveness, interpersonal skills, and medicines and health (General

131 Pharmaceutical Council 2018c).

132 Regulatory requirements for pre-registration training sites and tutors are limited and

133 lack specificity (General Pharmaceutical Council 2018d;Mills et al. 2013). Other than

134 demonstrating in an application form that the site is suitable for trainees to develop

135 competence and complete performances standards, there is no system of

136 accreditation, assessment or quality assurance of training sites/ premises. To

137 become a pre-registration tutor, the only requirements are that one must be a

138 registered pharmacist who has been practising in the sector of pharmacy in which

139 the tutor wishes to supervise for 3 years or more and must not be under investigation

140 by the GPhC (General Pharmaceutical Council 2018d).

141 There has been a dearth of evidence on whether the current arrangements for pre-

142 registration training and assessment support the development of appropriate

143 competences necessary for practice as a newly qualified pharmacist. In 2013/14,

144 the GPhC surveyed trainees and tutors to collect feedback about pre-registration

145 training experiences (Blenkinsopp et al. 2015;Marshall et al. 2016). Findings from

146 the survey of trainees (Marshall, Roberts, \& Wisher 2016) showed that those who

147 trained in the hospital sector were more likely to report that pre-registration training

148 prepared them to be a pharmacist than community trainees ( $83 \%$ vs. $77 \%$ ), that the

149 training experience was of good/ very good quality ( $89 \%$ vs. $74 \%)$ and that they

150 received good/ excellent supervision (72\% vs. 56\%) (Marshall, Roberts, \& Wisher

151 2016).

152 The survey of pre-registration tutors showed that the majority of respondents $(76 \%)$

153 agreed they had access to sufficient support, 16\% neither agreed or disagreed and

$1548 \%$ disagreed or strongly disagreed, impacting in turn on the quality of the trainee

155 experience (Marshall, Roberts, \& Wisher 2016). However, very little research has

156 been conducted to unravel what happens during pre-registration to shape the

157 development of trainees; it has remained a 'black-box'. 
158 The aim of this paper, therefore, is to present findings from a longitudinal study into 159 how pre-registration training supports the development of pharmacy trainees prior to 160 registered practice, thus offering possible explanations for the differences in 161 outcomes. This paper focuses on the qualitative findings which capture issues in 162 the equity and robustness of the pre-registration year.

\section{Methods}

164 A longitudinal mixed methods study tracked a group of 20 trainees and their tutors 165 throughout pre-registration training and early practice in 2011/12 (Jee 2014; Jee et al. 166 2016a;Jee et al. 2016b). Participants were purposely sampled to capture a diverse 167 range of community pharmacies (supermarkets; independents; large chains) and 168 hospitals (district general hospitals; teaching hospitals), male and females and 169 geography (rural; urban).Six trainee-tutor pairs were recruited from hospital and 14 170 from a range of community pharmacy settings. Each trainee was interviewed at 4 171 time points: the beginning of the training year, at months 4 and 9 during training, and 172 at 3 months post-registration; tutors were interviewed twice: at months 4 and 9.

173 Interview schedules focused on learning and development, work environment, 174 support structures (including tutor), assessment and feedback mechanisms.

175 Questions were developed through literature on professional development / 176 socialisation in the health professions and piloting questions with several trainees 177 and tutors. Research bias was mitigated through sampling, avoiding leading 178 questions and encouraging honest conversations in private. Interviews were audio179 recorded, transcribed verbatim and transcripts were analysed thematically using 180 template analysis (King 2004). University ethics committee approval was granted; 181 more detail on the methods has been published elsewhere (Jee, Schafheutle, \& 182 Noyce 2016a;Jee, Schafheutle, \& Noyce 2016b).

\section{Results}

184 Of the twenty trainees, 11 were female; 21 tutors were involved (1 was replaced), 11 185 were female. They were purposively recruited in North-West England. The findings 186 from this study are presented to offer insights into the environment of pre-registration 187 training sectors and settings, the support trainees received and their assessment. 
188 Quotes from all four rounds of interviews are used for illustration, identifying tutor vs. 189 trainee, and sector of training.

\section{$190 \quad 3.1 .1$ Training settings}

191 The study highlighted key differences between the pre-registration training 192 experience between settings (size of setting, services offered, patient mix) and 193 particularly sector, i.e. community vs. hospital.

194 Community

195 Community pharmacies offering pre-registration training included smaller 196 independent pharmacies through to larger chain and supermarket pharmacies. The 197 provision of services delivered to patients was not consistent across community 198 training sites, so all trainees may not have experienced delivery of a comprehensive 199 or comparable range of services during pre-registration training. The different types 200 of patients and their respective clinical presentations also differed across training 201 sites.

202

203

204

205

Community trainees would usually deal with patients themselves as well as 'proxy customers' (i.e. carers; family members etc.), many of whom were regular visitors allowing longer term rapport and relationships to be built. Community trainees became more accustomed to drugs used in the long-term management of chronic conditions, as well as over-the-counter medicines used for the treatment of minor ailments.

"In this store - the scope of what we do here is quite limited ... we're not next to the surgery or anything. So, as I say, there aren't that many clinical problems to deal with." (Trainee 8, community - large multiple, round 2)

215 Hospital

216 Hospital pre-registration training was undertaken in large university teaching 217 hospitals or smaller district general hospitals. Trainees in hospital were exposed to 218 different specialisms on ward rotations (e.g. intensive care; renal; cardiac). Trainees 
219 in teaching hospitals were more likely to encounter patients with rare health

220 conditions and high numbers of patients in comparison to those in district general

221 hospitals. Unlike in community settings, hospital patients may have been critically ill

222 or bed-bound, and their stays were often time-limited, so established rapport was

223 short-term. Additionally, hospital trainees learnt about drugs used in acute care and

224 a wide range of clinical specialties.

225 I've done a rotation on a children's ward and that improved my knowledge of 226 prescribing in children, the doses that the regular prescribed medications are 227 given in children and what would be normal doses and what would be abnormal. And then I did a rotation in palliative care, so I gained an insight into end of life care there and the doses and kind of drugs that they used." (Trainee 11, hospital - district general, round 2)

231

\subsubsection{Support and development systems}

232 Analysis showed that the way in which trainees were supported by staff, both

233 formally and informally (e.g. through role modelling) differed across settings and

234 particularly between community and hospital sectors.

235 Community

236 In community pharmacy, trainees worked within a smaller team, usually consisting of 237 just 1 pharmacist, their pre-registration tutor, and a range of other pharmacy support 238 staff. Community trainees worked closely with their tutors, who also served as the 239 main role model and key source of support. However, they also acted as assessors, 240 as they were responsible for signing off trainees' achievement of performance 241 standards, captured in a portfolio and satisfactory performance during 13-weekly 242 appraisals.

"[Tutor]'s been the most helpful 'cos she knows most of the stuff and she's the

246 Community trainees received the majority of feedback from their tutor, and

247 commonly this would take place during formal 13-weekly appraisals. In the main this 248 was based on direct observation due to close working in a small team. 
260

261

262

263

264

265

266

267

268

269

270

271

272

273

274

275

276

277

278

279

280

"She [My pre-reg tutor] said that she's seen me do a lot of things in the pharmacy which, just based on [that], she'll be able to sign me off on some performance standards." (Trainee 12, community - supermarket, round 2)

More informal feedback (received both from their tutor and other staff) was only occasional and, if received, this tended to be following trainees' lapses in performance or errors, rather than being constructive or praising good performance. "I mean, it's always difficult because, especially being a busy pharmacy, there's always so many other things going on that it's difficult to spend as much time as you want to with the trainee. You know, I would have ideally liked to have spent more time with him - and I probably don't give as much positive feedback as I should." (Tutor 4, community - supermarket, round 3)

In community pharmacy, trainees were typically supervised by 1 pharmacist (their tutor), though some larger community pharmacies had a second pharmacist. Particularly in the early stages of the pre-registration year, trainees cited nonpharmacist staff, such as pharmacy technicians, dispensers and counter assistants, as playing a significant role in supporting them in the work setting. They supported trainees' learning, particularly in gaining proficiency in dispensing and adjusting to the working processes. As tutors, these support staff were seen as role models. "The counter assistant I think she knows how to deal with the patients. Her knowledge of over the counter products is very good." (Trainee 12, community supermarket, round 1)

Some trainees also worked collaboratively with local General Practitioners (GPs) depending on the proximity of, and working relationship with, the GP practice. "I think people have been working with each other for so long that they're just accustomed to each other so it's like they're a family, so obviously now I'm here I am fitting in as well." (Trainee 16, community - large multiple, round 1) In hospital pharmacy, trainees commonly worked with a range of different pharmacists. Whilst each trainee was assigned their own pre-registration tutor, responsibility for supervising trainees was often shared amongst multiple pharmacists. Trainees also worked alongside a wide range and large number of pharmacy support staff, such as pharmacy technicians and assistant technical officers. Furthermore, whilst on different ward rotations, trainees were exposed 
to multidisciplinary teams and a range of other healthcare professionals, such as doctors and nurses.

"I've had more experience sort of speaking to doctors and nursing staff and other staff on ward level. So l'd say communication skills and sort of confidence and things has developed." (Trainee 11, hospital - district general, round 3)

Hospital

Hospital tutors commonly delegated some teaching and feedback functions to others, particularly pharmacist colleagues, and collated information on trainees' development from different sources prior to conducting appraisals and signing off trainees' performance standards. Whilst many individuals were involved in supervising and supporting trainees in hospital pharmacy, they did not always provide feedback. It appeared that tutors would ask to receive feedback from the trainees' rotations, so that this could feed into trainees' 13-weekly appraisals, but this did not always occur. Most formal feedback for trainees was provided by tutors in 13-weekly appraisals. Informal feedback was generally considered to be lacking and would often focus on anything below standards, there was not much about praise or aspiring to excellence.

"I've not actually been witness to what he's been doing on the wards. But, again, we have had evidence that he is doing that on the wards because that's been signed off by another pharmacist." (Tutor 11, hospital - district general, round 3)

It was notable that trainees in both hospital and community pharmacy focussed much of their time and attention on preparing for the registration assessment, which was towards the end of the pre-registration year in June. This probably took trainees' focus away from making the most of the in-practice learning opportunities, in favour of a more traditional model of revision and exam preparation.

\subsubsection{After pre-registration training: Practice as a newly qualified pharmacist}

Findings relating to the 4th set of interviews with newly qualified pharmacists (NQPs) showed how NQPs faced challenges with holding full accountability as registered pharmacists. Trainees had no experience of taking full responsibility during the preregistration year, when they were supervised and deferred to their tutor.

\section{Community}


312 As most NQPs in community practised as sole pharmacists, they often referred to 313 other support staff, who tended to have considerable pharmacy experience, if they 314 were unsure. Support staff could also be a resource for learning how to deliver 315 unfamiliar services. Interview findings showed that some NQPs talked about 316 referring to a more senior manager within the organisation for help and support.

317 "Yeah, I mean because now I'm a pharmacist, like I'm sort of on top of like in the 318 chain of command, if you get me, so they're supposed to listen to me, whereas 319 as a pre-reg it was the other way round. So that's definitely changed." (Trainee 3201 , community - large multiple, round 4)

321 Hospital

322 None of the NQPs working in hospital felt isolated in their working practices, as they 323 worked within a large team of pharmacists, pharmacy support staff and other 324 healthcare professionals. Two NQPs, working as residents, pointed out that 325 pharmacists positioned slightly above them, such as the second year resident 326 pharmacists were particularly helpful to them. Nevertheless, there was still a feeling 327 of lack of preparedness for full responsibility and accountability.

328 So yeah, [pre-registration training] has helped me but at the same time I don't 329 think anything can prepare you for the feeling of I'm actually totally responsible 330 for everything that I do now. Like, you know, we got told about it but nothing can 331 actually prepare you for that feeling." (Trainee 17, hospital - teaching, round 4)

\section{Discussion}

333 This paper has brought together evidence form the pharmacy regulator in Great 334 Britain, the General Pharmaceutical Council (GPhC), which has shown that pre335 registration pharmacists who trained in community pharmacy were less satisfied with 336 their training experience (Marshall, Roberts, \& Wisher 2016) and were also less 337 likely to pass the final pre-registration assessment (Andalo 2015; Torjesen 2015) than 338 their hospital colleagues. It used the first in-depth longitudinal study of pre339 registration trainees and their tutors to offer possible explanations for these 340 differences. This study highlighted differences in pre-registration trainees' learning 341 and development opportunities and experience across training sites and between 342 sectors (hospital and community), support and assessment mechanisms, and 343 trainees', and particularly newly qualified pharmacists' (NQPs), need for positive and 
344 constructive support and transition into independent practice. Ensuring consistency

345 and equity across sectors and settings, assuring quality of the training experience,

346 and having robust formative and summative assessment methods are key areas to

347 focus on improving.

348 The insights from GPhC trainee satisfaction surveys (Marshall, Roberts, \& Wisher

349 2016) and analysis of pass rates by sector of training (Andalo 2015; Torjesen 2015),

350 in combination with the detailed findings from this study, call into question the ability

351 for single sector training to offer trainees the range of competencies they require for

352 practice as a day-1 pharmacist (Magola et al. 2018a). This is particularly important

353 as NQPs can practise in any sector upon registration, regardless of previous

354 experience. The GPhC has become more aware of concerns about the range and

355 consistency in training experiences during pre-registration training. Discussions at a

3562016 event with key stakeholders and the GPhC (General Pharmaceutical Council

357 2016), noted that further actions were needed to improve pre-registration training,

358 including the need to identify gaps in knowledge and training of day-1 pharmacists.

359 Availability and suitability of support structures for pre-registration trainees and

360 NQPs need to be evaluated for their appropriateness. Firstly, the GPhC does not

361 currently monitor or accredit pre-registration training premises, and there is no clear

362 specification about the required training resources these pharmacy sites need to

363 have. In contrast, schools of pharmacy offering MPharm progammes must be

364 accredited by the GPhC, which involves demonstrating how an MPharm curriculum

365 meets revised outcomes-focussed education and training standards (General

366 Pharmaceutical Council 2011). Whilst other regulators, such as the NMC (Nursing \&

367 Midwifery Council 2018), have more powers with placements being within the degree

368 and universities face scrutiny as part of this, pharmacist pre-registration is currently

369 disjointed, with pre-registration training following after completion of an MPharm

370 degree. There may be other options though, as the GPhC is unusual, in that it

371 regulates not only pharmacy professionals but also registered premises, so may

372 have opportunity to include additional requirements for training premises, which

373 could then be part of regular GPhC inspections.

374 Approval of neither pre-registration tutors nor training premises is dependent on

375 outcomes, such as trainees' experience or assessment failure. The pre-registration

376 tutor appears fundamental in supporting the development of trainees. However, 
377 tutors do not have to undergo training or demonstrate appropriate competencies to 378 supervise pre-registration training. There is instead guidance (General

379 Pharmaceutical Council 2014) and development resources (General Pharmaceutical 380 Council 2014) available for tutors to access. There may be a need to consider more 381 training and support for tutors, which some appear to find inadequate (Jee, 382 Schafheutle, \& Noyce 2016b). The regulator has acknowledged that further actions 383 are needed to support tutors and hold them to account for signing off trainees in 384 appraisals/ reviews (General Pharmaceutical Council 2016).

385 Recommendations have previously been made to have a system in place for 386 assessing the competence of tutors against defined standards, and the need for tutor 387 training and support networks to be put in place (Cooper et al. 2009;Seston and 388 Hassell 2009). There appears to be a need to support tutors with training and to 389 have a stronger system of quality assurance checking of tutors. Indeed, Health 390 Education England (HEE), who hold responsibility for the delivery of high quality 391 education and training for the healthcare workforce in England, have recognised this 392 need and are working on enhancing the current pre-registration pharmacist training, 393 through, for example, the introduction of an e-portfolio and improved access to tutor 394 training (Bradley et al. 2017; Health Education England 2018).

395 NQPs can practise in any setting or sector of pharmacy, so it is important that 396 pharmacists begin registered practice with the full range of competences required for 397 safe and effective practice. There is a need to support NQPs as they transition into 398 taking responsibility for their own and their team's - particularly in the case of 399 community pharmacy - practice (Magola, Willis, \& Schafheutle 2018a). Many NQPs 400 working in community pharmacy will practise in relative isolation (Cooper, Bissell, \& 401 Wingfield 2009) as the sole pharmacist. Hospital pharmacists typically have a 402 network of informal support through working with other pharmacists on a regular 403 basis. Additionally, hospital pharmacists will usually undertake further training in the 404 form of a clinical diploma, typically after 2 years of practice, but community 405 pharmacists - representing the majority of the pharmacy workforce (Phelps et al. 406 2014) - often do not undertake any further qualifications.

407 A foundation programme to support pharmacists has been set up by the professional 408 body, the Royal Pharmaceutical Society (RPS). The programme caters to members 409 in their first 1000 days of practice, as well as members returning to work after a 
410 career break or are changing practice environment (Royal Pharmaceutical Society

411 2018). The need to 'bridge the gap' of transition from pre-registration trainee to

412 pharmacist has, nevertheless, been recognised by the chief pharmaceutical officers

413 of England, Wales and Scotland (Wilkinson 2018). Drawing on systems and

414 evidence from other professions, particularly nursing and medicine, some research is

415 emerging to inform evidence based support interventions (Magola et al. 2017; Magola

416 et al. 2018b).

417 Whilst other healthcare professions such as medicine and nursing have NHS training

418 contracts for the provision of education and training, the same arrangements are not

419 in place in pharmacy. Although a standard grant is paid as part of the NHS

420 pharmacy contract to owners, the terms and conditions of pre-registration trainees

421 (e.g. salaries, hours, study time, duties) are determined by individual pharmacy

422 employers. For example, in community pharmacy, the training grant is paid to the

423 pharmacy owner, but pharmacy tutors are generally pharmacist employees so there

424 is no direct link between remuneration and incentivisation of tutors. The exception in

425 GB is Scotland, where NHS Scotland manages pre-registration training centrally

426 (NHS Education for Scotland 2018). In Scotland, recruitment for pre-registration

427 training positions in community and hospital is done through NHS Education for

428 Scotland (NES) and there are standardised elements of pre-registration training in

429 pharmacy (NHS Education for Scotland 2018).

430 This Scottish approach to training governance (i.e. a deanery-type structure as with

431 medicine) or some other responsive monitoring system is needed to provide quality

432 support and control for pharmacist pre-registration training. There are plans to

433 integrate the pre-registration year with the MPharm into a 5-year degree programme,

434 but how this will be operationalised is not yet known (Smith and Darracott 2011).

435 These changes may support quality assurance of training through quality control

436 measure put in place in cooperation with pharmacy employers and Schools of

437 Pharmacy.

438 There appears to be a lack of awareness of the pattern of changes in professional

439 behaviour that occur within the pre-registration period, though findings from the

440 longitudinal research presented here shed light on this previously under-researched

441 area. The types of assessment that are taking place during training may need to be

442 reviewed to see if they are consistent and measure the full range of skills necessary 
443 for practice as a day-1 pharmacist in any sector. The current use of a competency 444 portfolio used to record progress may have shortcomings itself, particularly as there 445 is a lot of dependence on the pre-registration tutor to deem a trainee satisfactory in 446 the 13-weekly performance reviews. An assessment system that uses a variety of 447 standardised workplace assessment tools throughout the training period to monitor 448 progress, particularly in the development of behavioural skills, should be explored. 449 Furthermore, triangulation of assessments should also be considered, echoing 450 recommendations made by others (Seston \& Hassell 2009).

\section{Conclusion}

452 Pharmacy pre-registration training is a critical year that paves the way to registration 453 as a pharmacist. Therefore, it is crucial that there is consistency in the development 454 of core knowledge and skills and their application for all pre-registration trainees. 455 Support for trainees, as well as tutors, must be sufficient and support systems for 456 newly qualified pharmacists (NQPs) should be considered to facilitate transitions into 457 practice. NQPs are considered as general pharmacy practitioners, and can practise 458 in any sector of pharmacy. The variability of training provision in pre-registration 459 training, and the absence of formal arrangements for support or supervision 460 immediately post-registration, pose unnecessary systematic risks to patient safety 461 and the wellbeing of the pharmacist workforce. Assessment methodology must also 462 be sufficiently robust and facilitate learning and development in a fair way. Together, 463 this will improve the overall consistency, equity and quality of pre-registration 464 training.

\section{Declaration of conflicting interests}

467 The Authors declare that there is no conflict of interest.

468

469 Funding acknowledgement

470 This research received no specific grant from any funding agency in the public, 471 commercial, or not-for-profit sectors. 


\section{References}

474 Pharmacy Integration Fund. www.england.nhs.uk/commissioning/primary-

475 care/pharmacy/integration-fund/ . 2016. NHS England. accessed 13 Aug 2018.

476

477 Adams, N. \& Grieder, D.M. 2014. Treatment Planning for Person-Centred Care: Shared

478 Decision Making for Whole Health, 2 ed. Academic Press, Elsevier.

479 Andalo, D. 2015. Preregistration training: Disparity between pass rates is cause for concern, 480 says GPhC. Pharmaceutical Journal, 295, (7881) 263

481 Blenkinsopp, A., Marshall, K., McNair, K., Robert, G., \& Wisher, S. 2015, General

482 Pharmaceutical Council Survey of 2013/14 Pre-registration Tutors, University of Bradford \&

483 GPhC, London.

484 Bradley, F., Schafheutle, E.I., \& Willis, S.C. 2017. Building capability of pre-registration 485 pharmacist tutors: evaluation of training. International Journal of Pharmacy Practice, 25, 486 (Suppl. 2) 38

487 Burge, S.M. 2003. Undergraduate medical curricula: Are students being trained to meet 488 future service needs? Clinical Medicine, Journal of the Royal College of Physicians of 489 London, 3, (3) 243-246

490 Cooper, R.J., Bissell, P., \& Wingfield, J. 2009. 'Islands' and 'doctors's tool': The ethical 491 significance of isolation and subordination in UK community pharmacy. Health, 13, (3) 297$492 \quad 316$

493 General Pharmaceutical Council 2011, Future Pharmacists. Standards for the initial 494 education and training of pharmacists, GPhC, London.

495 General Pharmaceutical Council 2014. Guidance on tutoring for pharmacists and pharmacy 496 technicians London, GPhC.

497 General Pharmaceutical Council. GPhC releases addtional pass rate information.

498 www.pharmacyregulation.org/news/gphc-releases-additional-pass-rate-information . 15-10499 2015a. accessed accessed 13 Aug 2018.

500

501

502

General Pharmaceutical Council 2015b, Pass rates for the GPhC's Registration Assessment by school of pharmacy, GPhC.

503 General Pharmaceutical Council 2016, Roundtable on the future of pre-registration 504 pharmacist training in England: 3 February 2016. Event report, GPhC, London.

505 General Pharmaceutical Council. June registration assessment results - published each 506 year. www.pharmacyregulation.org/news/results-june-registration-assessment-announced. 507 2018a. accessed 13 Aug 2018.

508

509

510

511

512

513 General Pharmaceutical Council 2018c, Pharmacist Pre-Registration Manual. Version 5.7. 
514 General Pharmaceutical Council. Pre-registration training placement. 515 www.pharmacyregulation.org/pre-registration-training-placement . 2018d. accessed 13 Aug 5162018

517

518

519

520

Greiner, A.C., Knebel, E., Committee on the Health Professions Education Summit, \& Board on Health Care Services 2003. Health Professions Education: A Bridge to Quality Washington, DC, The National Academies Press.

521 Health Education England. Pharmacy. www.hee.nhs.uk/our-work/pharmacy . 2018.

522 accessed 13 Aug 2018.

523

524

525

526

Jee, S. 2014. The process of professional socialisation and development of professionalism during pre-registration training in pharmacy. $\mathrm{PhD}$ (PhD Thesis). The University of Manchester.

527 Jee, S.D., Schafheutle, E.I., \& Noyce, P.R. 2016a. Exploring the process of professional 528 socialisation and development during pharmacy pre-registration training in England.

529 International Journal of Pharmacy Practice, 24, 283-293

530 Jee, S.D., Schafheutle, E.I., \& Noyce, P.R. 2016b. Using longitudinal mixed methods to 531 study the development of professional behaviours during pharmacy work-based training. 532 Health \& Social Care in the Community, 25, (3) 975-986

533 King, N. 2004, "Using templates in the thematic analysis of texts," In Qualitative Methods 534 and Analysis in Organisational Research: A Practical Guide, G. E. Symon \& C. E. Cassell, 535 eds., London: SAGE, pp. 256-270.

536 Lloyd-Jones, G. 2005. Beyond 'tomorrow's doctors': A review of basic medical education in 537 the UK. Annals of Tropical Paediatrics, 25, (2) 71-78

538 Magola, E., Willis, S., \& Schafheutle, E.I. 2017. Evaluation of a group coaching programme 539 to support the transition of newly-qualified community pharmacists. International Journal of 540 Pharmacy Practice, 25, (Suppl. 2) 40-41

541 Magola, E., Willis, S.C., \& Schafheutle, E.I. 2018a. Community pharmacists at transition to 542 indepedent practice: isolated, unsupported and stressed. Health \& Social Care in the 543 Community, DOI: 10.1111/hsc.12596,

544 Magola, E., Willis, S.C., \& Schafheutle, E.I. 2018b. What can community pharmacy learn 545 from the experiences of transition to practice for novice doctors and nurses? A narrative 546 review. International Journal of Pharmacy Practice, 26, (1) 4-15

547 Marshall, K., Roberts, G., \& Wisher, S. 2016, Analysis of Trainee Dissatisfaction - 2013-2014 548 Pre-registration Pharmacist Trainees, General Pharmaceutical Council, London.

549 McAteer, S., John, D., \& Luscombe, D.K. 2004. Views of pre-registration graduates on the 550 UK pharmacy undergraduate course as preparation for pre-registration training. International 551 Journal of Pharmacy Practice, 12,

552 Mills, E., Blenkinsopp, A., \& Black, P. 2013. Quality management in pharmacy pre553 registration training: Recommendations for the future. Pharmacy Education, 13, (1) 87-92

554 NHS Education for Scotland. Pre-Registration Pharmacist Scheme.

555 www.nes.scot.nhs.uk/education-and-training/by-discipline/pharmacy/pre-registration-

556 pharmacist-scheme.aspx. 2018. accessed 13 Aug 2018. 
$558 \quad$ Nursing \& Midwifery Council. Standards for education.

559 www.nmc.org.uk/education/standards-for-education2/. 2018. NMC. accessed 13 Aug 2018.

560

561

Parmar, H. 2016. Views of Manchester Pharmacy Graduates and Pre-registration Tutors on

562 Preparedness for Pre-Registration Training. MPhil The University of Manchester.

563 Parmar, H., Schafheutle, E., Willis, S., \& Silkstone, V. 2016. MPharm graduates'

564 preparedness for practice relating to interpersonal skills after curricular reform. International

565 Journal of Pharmacy Practice, 24, (Suppl. 1) 31-32

566 Pharmacist Support. The pre-registration training grant. https://pharmacistsupport.org/fact-

567 sheets/pre-registration-training-grant/. 2018. accessed 13 Aug 2018.

568

569

Phelps, A., Agur, M., Nass, L., \& Blake, M. 2014. GPhC Registrant Survey 2013. Findings

570 London, NatCen \& General Pharmaceutical Council.

571 Royal Pharmaceutical Society. Foundation Programme. www.rpharms.com/professional-

572 development/foundation-programme. 2018. accessed 13 Aug 2018.

573

574

575

576

577

578

579

Schafheutle, E.I., Hassell, K., Ashcroft, D.M., Hall, J., \& Harrison, S. 2012. How do pharmacy students learn professionalism? International Journal of Pharmacy Practice, 20, 118-128

Schafheutle, E.I., Hassell, K., Ashcroft, D.M., \& Harrison, S. 2013. Organizational philosophy as a new perspective on understanding the learning of professionalism. American Journal of 580 Pharmaceutical Education, 77, (10) Article 214

581 Seston, L. \& Hassell, K. 2009, Pharmacy Workforce Census 2008: Main findings, RPSGB \& 582 CPWS, London \& Manchester.

583 Smith, A. \& Darracott, R. 2011. Modernising Pharmacy Careers Programme. Review of 584 pharmacist undergraduate education and pre-registration training and proposals for reform. 585 Discussion paper London, Medical Education England. Crown copyright.

586 Toklu, H.Z. \& Hussain, A. 2013. The changing face of pharmacy practice and the need for a 587 new model of pharmacy education. Journal of Young Pharmacists, 5, (2) 38-40

588 Torjesen, I. 2015. Pass rates for GPhC registration exam vary between universities.

589 Pharmaceutical Journal, 294, (7863/4) online: DOI: 10.1211/PJ.2015.20068574

590 Wilkinson, E. 2018. Bridging the gap: CPOs back foundation training plan. Pharmaceutical 591 Journal, 300, (7913) 279-281

592

593 